\title{
Atividade alelopática de extratos de diferentes orgãos de Caesalpinia ferrea na germinação de alface
}

\author{
Allelopathic activity of extracts from different organs of Caesalpinia ferrea on lettuce germination
}

\author{
Andreya Kaliana de Oliveira ${ }^{\mathrm{I}}$ Maria de Fatima Barbosa Coelho ${ }^{\mathrm{I}^{*}}$ Sandra Sely Silveira Maia $^{\mathrm{I}}$ \\ Francisco Esio Porto Diógenes ${ }^{I}$
}

\section{RESUMO}

A alelopatia pode afetar muitos aspectos da ecologia das plantas, incluindo a ocorrência, crescimento, sucessão de plantas, estrutura das comunidades, dominância, diversidade e produtividade. Neste trabalho, o objetivo foi avaliar o potencial alelopático de diversos órgãos de jucá (Caesalpinea ferrea) sobre a germinação de sementes $e$ desenvolvimento de plântulas de alface (Lactuca sativa). Foi usado o delineamento experimental inteiramente casualizado no esquema fatorial $2 \times 5$, com dois métodos de extração (25 e $\left.100^{\circ} \mathrm{C}\right)$ e cinco concentrações do extrato bruto $(0,25,50,75 e$ $100 \%)$ para cada órgão avaliado: folhas, cascas e vagens maduras de $\boldsymbol{C}$. ferrea, em quatro repetições de 25 sementes da alface 'Mônica SF FI'. As características avaliadas foram porcentagem de germinação (PG), índice de velocidade de germinação (IVG), porcentagem de plântulas normais $(P N) e$ anormais (PA), comprimentos da parte aérea (CPA) e da raiz (CR) de plântulas de alface. Os extratos de folhas e de vagens de $\boldsymbol{C}$. ferrea obtidos a quente $\left(100^{\circ} \mathrm{C}\right)$ reduziram a porcentagem de germinação de $\mathbf{L}$. sativa em relação à testemunha (0\%). Nas maiores concentrações dos extratos de todos os órgãos, houve alta PA (atrofiamento da raiz, queima e escurecimento da radícula, encurvamento do caulículo, geotropismo negativo) e menor CPA e CR, comparado à testemunha. Os extratos dos diferentes órgãos de $\mathbf{C}$. ferrea apresentam atividade alelopática inibindo o desenvolvimento de plântulas de alface.

Palavras-chave: Jucá, Lactuca sativa L., aleloquimicos, planta daninha.

\section{ABSTRACT}

Allelopathy can affect many aspects of plant ecology, including the occurrence, growth, plant succession, community structure, dominance, diversity and productivity of plants. The aim of this study was to evaluate the allelopathic potential of various organs of jucá (Caesalpinea ferrea) on seed germination and seedling development of lettuce (Lactuca sativa). It was used in a completely randomized $2 \times 5$ factorial arrangement, with two extraction methods $\left(25\right.$ and $\left.100^{\circ} \mathrm{C}\right)$ and concentrations of crude extract $(0,25,50,75$ and 100\%) for each organ evaluated: leaves, stem bark and mature pods of $\boldsymbol{C}$. ferrea in four replications of 25 seeds of lettuce 'Monica SF FI'. The characteristics evaluated were germination percentage $(P G)$, germination speed index (IVG), percentage of normal seedlings (PN) and abnormal (PA), shoot length (CPA) and root length (CR) of lettuce seedlings. The extracts of leaves and pods of $\mathrm{C}$. ferrea obtained the hot $\left(100^{\circ} \mathrm{C}\right)$ reduced the germination percentage of $\mathbf{L}$. sativa compared to control (0\%). At higher concentrations of the extracts of all organs were high PA (atrophy of the root, burning and darkening of the radicle, the bending caulículo, negative geotropism) and lower CPA and CR compared to control. The extracts of different organs of $\boldsymbol{C}$. ferrea show allelopathic activity affecting the development of lettuce seedlings.

Key words: Jucá, Lactuca sativa L., allelochemicals, weed.

\section{INTRODUÇÃO}

O termo alelopatia é definido como "a interferência positiva ou negativa que compostos do metabolismo secundário produzidos por uma planta exercem sobre outros organismos (plantas, insetos, fungos e algas) (FERREIRA \& AQÜILA, 2000). Os efeitos alelopáticos possuem várias utilizações na agricultura, tais como, contribuir na busca por novos defensivos agrícolas, compreender o antagonismo de cultivos consorciados ou sucessivos, diminuir o uso

IPrograma de Pós-graduação em Fitotecnia, Universidade Federal Rural do Semi Árido (UFERSA), CP 137, 59625-900, Mossoró, RN, Brasil. E-mail: coelhomfstrela@gmail.com. *Autor para correspondência. 
de herbicidas sintéticos, substituindo-os por herbicidas naturais (BRASS, 2009).

Diferenças nas respostas alelopáticas de compostos de diferentes órgãos de uma mesma planta foram observados por DELACHIAVE et al. (1999) e SILVA et al. (2006). Nos estudos de alelopatia com espécies da caatinga, verificou-se que os extratos da polpa e da casca dos frutos de Ziziphus joazeiro Mart. apresentaram efeito alelopático desfavorável à germinação de sementes de $\boldsymbol{L}$. sativa dependendo da concentração (OLIVEIRA et al., 2009) e os extratos de sementes dessa espécie nas maiores concentrações afetaram a percentagem e velocidade de germinação e proporcionaram plântulas anormais (COELHO et al., 2011); o extrato de cascas de Mimosa tenuiflora (Willd.) Poir.) afetaram o desenvolvimento das plantas de alface, mas não reduziram a germinação em relação à testemunha (SILVEIRA et al., 2012).

Alguns autores já comprovaram o potencial alelopático de espécies da caatinga (CENTENARO et al., 2009; COELHO et al., 2011; RÊGO JUNIOR et al., 2011; SILVEIRA et al., 2012) e Caesalpinia ferrea Mart. ex Tul. var. ferrea (jucá) merece estudos nesse sentido por ser de ampla ocorrência na caatinga arbórea e arbustiva do nordeste brasileiro. Além disso, estudo fitoquímico preliminar do extrato hidroalcóolico da casca e das folhas de $\boldsymbol{C}$. ferrea demonstrou a presença de flavonoides, saponinas, taninos, cumarinas, esteroides e compostos fenólicos (LORENZI \& MATOS, 2008), que são reconhecidos por apresentarem atividade alelopática (RICE, 1984).

Assim, o objetivo neste trabalho foi verificar o efeito alelopático de extratos obtidos de diferentes órgãos de jucá sobre a germinação de sementes e o crescimento inicial de plântulas de alface.

\section{MATERIAL E MÉTODOS}

As folhas, cascas e vagens maduras de jucá utilizadas para a obtenção dos extratos foram coletadas no campus da Universidade Federal Rural do Semiárido (UFERSA) em outubro de 2009. Os diferentes órgãos de jucá foram acondicionados em sacolas de papel e levados ao laboratório de análise de sementes para se fazer a pesagem do material. Foram pesadas duas porções de $50 \mathrm{~g}$ de cada órgão da planta em balança de precisão, e cada uma delas passou por uma rápida assepsia (5min) em uma solução de hipoclorito de sódio (500ml de água destilada para $10 \mathrm{ml}$ de hipoclorito de sódio puro).

Depois da assepsia, cada material passou por um processo de secagem em papel toalha. Quatro porções de $50 \mathrm{~g}$ de cada órgão da planta foram acondicionadas separadamente em béqueres e colocouse em cada uma 500ml de água destilada em ebulição $\left(100^{\circ} \mathrm{C}\right)$. As outras quatro porções também foram acondicionadas em béqueres separadamente e receberam $500 \mathrm{ml}$ de água destilada à temperatura ambiente $\left(25^{\circ} \mathrm{C}\right)$. O material ficou em repouso por 30 minutos e depois cada conteúdo foi submetido a uma trituração em liquidificador doméstico por um minuto e, em seguida, passou por uma filtragem em pano tipo perfex $^{\circledR}$, no qual ficou retido todo o material fibroso. Assim, foram obtidos quatro extratos padrão à temperatura ambiente e quatro extratos padrão à temperatura de $100^{\circ} \mathrm{C}$.

Foram realizados quatro experimentos (um para cada órgão de jucá) no delineamento experimental inteiramente casualizado no esquema fatorial $2 \times 5$, com quatro repetições, com 25 sementes de alface da cultivar 'Mônica SF FI”, com percentual de germinação de 95\%, adquirida comercialmente na cidade de Mossoró-RN. Os dois métodos de extração foram a $25^{\circ} \mathrm{C}$ e a $100^{\circ} \mathrm{C}$ e as cinco concentrações do extrato padrão foram de 0 , 25, 50, 75 e 100\%, obtidas por diluição em água destilada (v/v). Em cada parcela experimental (caixa tipo gerbox devidamente esterilizada) foram colocados, com auxílio de uma seringa, $8 \mathrm{ml}$ do extrato sobre uma folha de papel filtro, previamente esterilizada em estufa a $105 \pm 3^{\circ} \mathrm{C}$ e, em seguida, as sementes de alface foram distribuídas uniformemente sobre o papel filtro. As caixas gerbox foram acondicionadas em câmara tipo BOD com temperatura de $25^{\circ} \mathrm{C}$ e fotoperíodo de $12 \mathrm{~h}$, durante sete dias.

O critério para avaliar a germinabilidade das sementes baseou-se no conceito de germinação fisiológica citada por MARCOS FILHO (2005), que aponta o início da germinação com a embebição da semente e seu final com a protrusão da radícula. A contagem de sementes germinadas foi realizada a cada 12 horas. A avaliação das plântulas ocorreu no sétimo dia após a semeadura, classificando-as em normais ou anormais, segundo critérios descritos em BRASIL (2009). A medição da parte aérea e da raiz de todas as plântulas normais foi feita com auxílio de um paquímetro digital devidamente regulado em $\mathrm{mm}$.

As variáveis analisadas foram porcentagem de germinação, porcentagem de plântulas normais e anormais, comprimento da raiz (distância em mm do colo até o ápice meristemático) e da parte aérea (distância em mm do colo até o ápice). O índice de velocidade de germinação (IVG) foi calculado de acordo com MAGUIRE (1962) pela fórmula IVG $=\mathrm{G}_{1} / \mathrm{N}_{1}+\mathrm{G}_{2} /$ $\mathrm{N}_{2}+\ldots+\mathrm{G}_{\mathrm{n}} / \mathrm{N}_{\mathrm{n}}$; em que: $\mathrm{G}_{1}, \mathrm{G}_{2}, \mathrm{G}_{\mathrm{n}}=$ número de sementes germinadas computadas na primeira, na segunda e na última contagem; e $\mathrm{N}_{1}, \mathrm{~N}_{2}, \mathrm{~N}_{\mathrm{n}}$ = número de dias da semeadura a primeira, segunda e última contagem. 
As variáveis obtidas em percentagem foram transformadas em raiz da variável +0,5 antes da análise de variância efetuada pelo programa estatístico SISVAR (FERREIRA, 2008). A análise de regressão foi aplicada para as concentrações dos extratos.

\section{RESULTADOS E DISCUSSÃO}

Extrato de folhas

Houve diferença significativa para métodos de extração, concentração do extrato e interação em todas as variáveis, com exceção da interação entre métodos e concentração para a variável porcentagem de germinação (Tabela 1). Todas as características apresentaram menor valor médio quando as sementes foram submetidas ao extrato obtido a $100^{\circ} \mathrm{C}$, com exceção da porcentagem de plântulas normais que foi maior no extrato a $25^{\circ} \mathrm{C}$. Possivelmente, esses resultados devem-se a maior disponibilidade dos aleloquímicos na solução quando se aplica extração a quente, visto que $\boldsymbol{C}$. ferrea apresenta elevado teor de taninos (FRASSON et al., 2003), os quais são mais facilmente solubilizados em água quente (TRUGILLO et al., 2003).

Diferentemente do presente estudo, os extratos aquosos de folhas de aroeira (Schinus terebinthifolius) reduziram a germinação de alface, independentemente da temperatura de extração (SOUZA et al., 2010) e os extratos de folhas de cagaita (Eugenia dysenterica) obtidos a temperatura ambiente $\left(25^{\circ} \mathrm{C}\right)$ foram mais eficientes em reduzir a germinação de alface do que os extratos a quente $\left(60^{\circ} \mathrm{C}\right)$ (GIOTTO et al., 2007). Por essa razão, é importante ressaltar as diferenças observadas entre a extração feita a frio e a quente, considerando-se os resultados do presente estudo, pois, mesmo não sendo uma técnica sugerida, o preparo de extratos com água quente é muito usado, visando a uma maior extração e à obtenção de substâncias menos solúveis da planta (FERREIRA \& AQÜILA, 2000).

A porcentagem de germinação (Figura 1A), o IVG (Figura 1B) e a porcentagem de plântulas normais (Figura 1C) na extração a $100^{\circ} \mathrm{C}$ apresentou relação de dose dependência com a concentração do extrato; à medida que a concentração aumentou, o valor médio dessas variáveis foi menor, enquanto a porcentagem de plântulas anormais aumentou com a concentração do extrato (Figura 1D). Resultados evidenciando a dependência dessas características e concentrações do extrato também foram obtidos por GATTI et al. (2004), que verificaram que os extratos de folhas de Aristolochia esperanzae reduziram a porcentagem de

Tabela 1 - Resumo da análise de variância para os efeitos da combinação de dois métodos de extração e cinco concentrações do extrato aquoso de folhas, cascas, vagens verdes e maduras de Caesalpinia ferrea Mart. ex Tul. var. ferrea para porcentagem de germinação (PG) de plântulas normais e anormais (PN e PA), índice de velocidade de germinação (IVG), comprimento da parte aérea e da raiz (CPA e CR) de L. sativa.

\begin{tabular}{|c|c|c|c|c|c|c|c|}
\hline & GL & PG & $\mathrm{PN}$ & PA & IVG & CPA & CR \\
\hline Mét. de Extração & 1 & $202,50^{*}$ & $231,34^{*}$ & $188,00^{*}$ & $0,69^{*}$ & $957,36^{*}$ & $153,86^{*}$ \\
\hline Concentração & 4 & $92,81^{*}$ & $23,38^{*}$ & $19,70^{*}$ & $0,51^{*}$ & $341,86^{*}$ & $1181,44^{*}$ \\
\hline Met.x Conc. & 4 & $50,93^{\mathrm{ns}}$ & $23,72^{*}$ & $18,13^{*}$ & $0,14^{*}$ & $76,32^{*}$ & $35,09^{*}$ \\
\hline Resíduo & 30 & 16,66 & 1,05 & 1,38 & 0,02 & 14,77 & 8,41 \\
\hline $\mathrm{CV}(\%)$ & & 4,22 & 14,82 & 22,03 & 12,20 & 21,97 & 16,37 \\
\hline Mét. de Extração & 1 & $0,62^{\mathrm{ns}}$ & $6502,50{ }^{*}$ & $\begin{array}{c}\text { o aquoso d } \\
6502,50^{*}\end{array}$ & S------- & $299,15^{*}$ & $26,79^{\text {ns }}$ \\
\hline Concentração & 4 & $4,06^{\mathrm{ns}}$ & $8142,18^{*}$ & $7854,58^{*}$ & $0,03^{* *}$ & $176,50^{*}$ & $834,43^{*}$ \\
\hline Met.x Conc. & 4 & $2,18^{\text {ns }}$ & $1547,81^{*}$ & $1385,31^{*}$ & $0,02^{\mathrm{ns}}$ & $16,80^{\mathrm{ns}}$ & $5,03^{\text {ns }}$ \\
\hline Resíduo & 30 & 3,95 & 42,91 & 47,50 & 0,10 & 11,03 & 7,28 \\
\hline \multirow[t]{2}{*}{ CV(\%) } & & 2,01 & 10,48 & 19,01 & 7,21 & 16,26 & 12,69 \\
\hline & 1 & $70,00^{*}$ & - & Ioso de vag & $\begin{array}{l}\text { duras-- } \\
0,65^{*}\end{array}$ & - & - \\
\hline Concentração & 4 & $158,43^{* *}$ & - & - & $0,72^{* *}$ & - & - \\
\hline Met.x Conc. & 4 & $75,93^{* *}$ & - & - & $0,29^{*}$ & - & - \\
\hline Resíduo & 30 & 18,75 & - & - & 0,08 & - & - \\
\hline $\mathrm{CV}(\%)$ & & 4,53 & - & - & 26,71 & - & - \\
\hline
\end{tabular}

${ }^{\mathrm{ns}}$ não significativo, ${ }^{*}$ significativo a $5 \% \mathrm{e}^{* *}$ significativo a $1 \%$ de probabilidade pelo teste $\mathrm{F}$.

- não ocorreram plântulas normais para fazer as análises. 

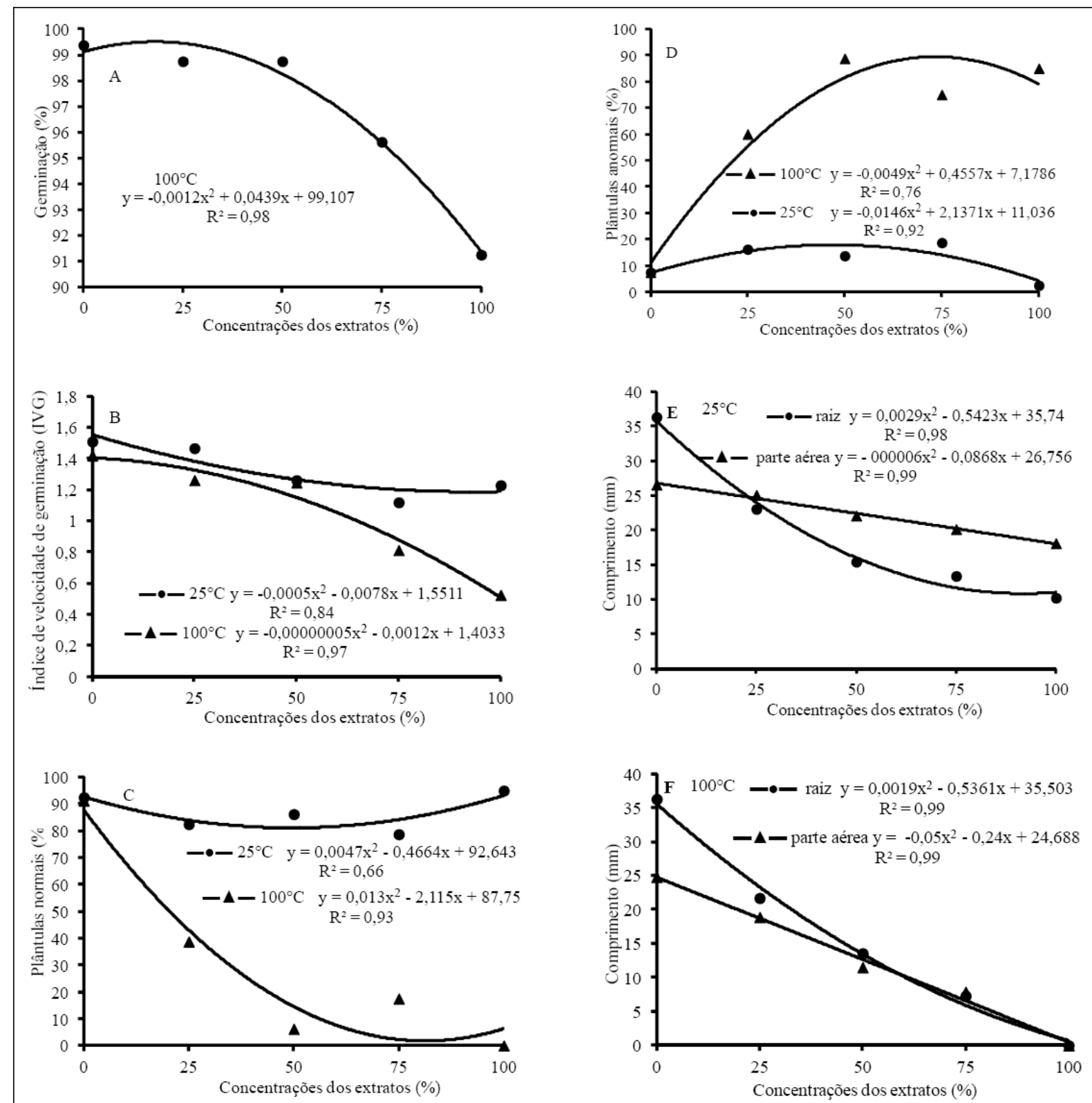

Figura 1 - Porcentagem de germinação (A), índice de velocidade de germinação (B), porcentagem de plântulas normais (C), de plântulas anormais (D), comprimento da parte aérea e da raiz no extrato a $25^{\circ} \mathrm{C}$ (E) e a $100^{\circ} \mathrm{C}(\mathrm{F})$ de Lactuca sativa $\mathrm{L}$. em diferentes concentrações do extrato aquoso de folhas de Caesalpinia ferrea Mart. ex Tul. var. ferrea .

germinação de sementes de alface a partir da concentração 50\%, sendo que as diferenças tornaramse mais acentuadas com o aumento da concentração.

O aparecimento de plântulas anormais, com raízes primárias atrofiadas e defeituosas, com ausência de raiz secundária e necrose radicular foi também observado por MARASCHIN-SILVA \& AQÜILA(2005, 2006) e BORELLA et al. (2009). Tal como observado no presente estudo, os extratos de raízes e de folhas de Raphanus raphanistrum provocaram alterações no índice de velocidade de germinação de sementes de alface (WANDSCHEER \& PASTORINI, 2008). Variações muito grandes nos parâmetros testados indicam perda de sincronia nas reações metabólicas da germinação, demonstrando heterogeneidade na fisiologia dos aquênios tratados (LABOURIAU \& AGUDO, 1987).

O comprimento da parte aérea e da raiz das plântulas de L. sativa também apresentou comportamento dependente da concentração do extrato 
(Figura 1E e F), mas o comprimento da raiz foi mais afetado. O extrato de folhas de Persea americana também causou o mesmo efeito em plântulas de alface (BORELLA et al., 2009). Esse maior efeito sobre as raízes possivelmente ocorre porque as raízes, por estarem em contato direto e prolongado com o extrato, em relação às demais estruturas das plântulas, são mais sensíveis às substâncias neles presentes.

\section{Extratos de cascas}

Os extratos de cascas de $\boldsymbol{C}$. ferrea não afetaram a porcentagem de germinação de sementes de alface, mas interferiram nas outras características (Tabela 1). O efeito mais drástico sobre o crescimento do que sobre a germinação foi também encontrado por PERIOTTO et al. (2004) em extratos de Andira humilis e por CARMO et al. (2007) em extratos de Ocotea odorífera.

A extração na temperatura de $100^{\circ} \mathrm{C}$ teve maior efeito na porcentagem de plântulas normais (Figura 2A) e no IVG (Figura 2C), quanto maior a concentração menor os valores dessas variáveis. Já a porcentagem de plântulas anormais (Figura 2B) e o comprimento da parte aérea e da raiz foi menor à medida que a concentração do extrato aumentou (Figura 2D), independente da temperatura de extração. As plântulas anormais apresentaram atrofiamento da raiz, queima e escurecimento da radícula, encurvamento do caulículo, geotropismo negativo, como já observado em outros estudos de alelopatia (SILVEIRA et al., 2012; COELHO et al., 2011, BORELLA et al., 2009; GATTI et al., 2004).

\section{Extratos de vagens maduras}

Houve diferença significativa para métodos, concentrações e interação métodos x concentrações para a porcentagem de germinação e IVG (Tabela 1). A porcentagem de germinação de alface (Figura 3A) e o IVG (Figura 3B) apresentaram relação de dose dependência com a concentração. A porcentagem de plântulas anormais foi $100 \%$ em todas as concentrações dos extratos de vagens maduras, de tal modo que não foi possível obter o comprimento da parte aérea e da raiz.

Todos os órgãos da planta têm potencial para armazenar aleloquímicos, mas a quantidade e o caminho pelos quais são liberados diferem de espécie para espécie (TAIZ \& ZEIGER, 2006). Por isso, as
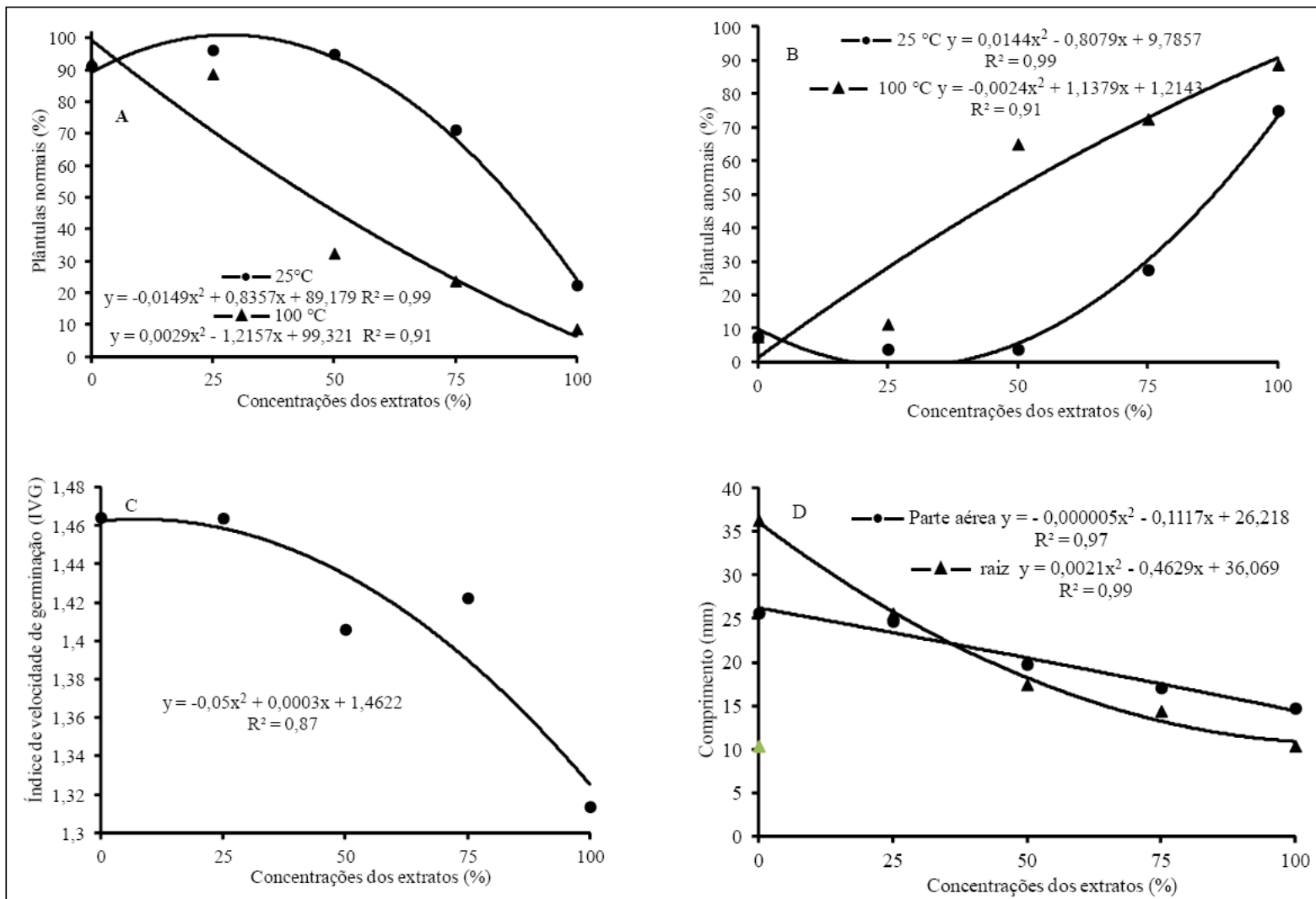

Figura 2 - Porcentagem de plântulas normais (A), de plântulas anormais (B), índice de velocidade de germinação (C) e comprimento da parte aérea e da raiz (D) de Lactuca sativa L. em diferentes concentrações do extrato aquoso de cascas de Caesalpinia ferrea Mart. ex Tul. var. ferrea obtido a $25^{\circ} \mathrm{C}$ e $100^{\circ} \mathrm{C}$. 


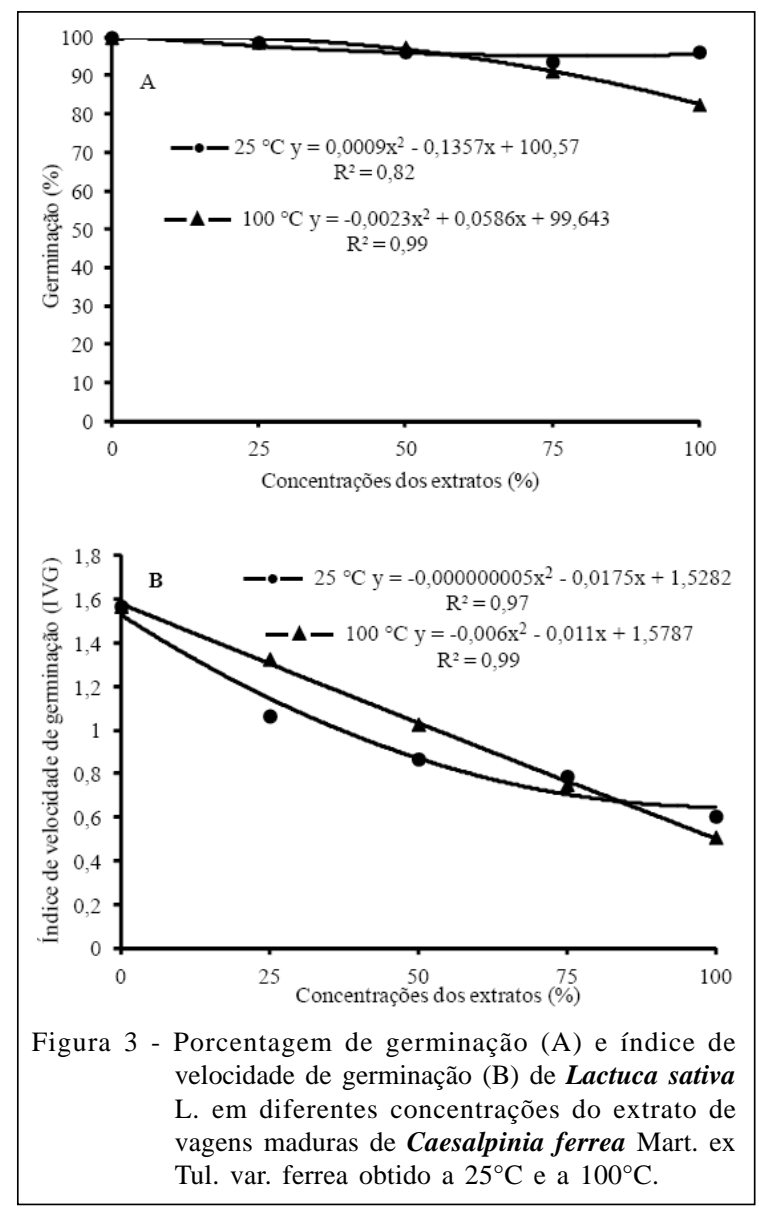

espécies apresentam diferentes atividades alelopáticas em seus órgãos, como já constataram GATTI et al. (2010) em Aristolochia esperanzae, SOUZA FILHO et al. (2010), em três espécies de Copaifera, COELHO et al. (2011), em Ziziphus joazeiro, e como foi comprovado no presente estudo com $\boldsymbol{C}$. ferrea. A presença de solanina, taninos, ácido gálico, ácido elágico e sistoterol nas folhas e frutos de $\boldsymbol{C}$. ferrea (SANTOS \& DANTAS, 2008), possivelmente está envolvida nos efeitos alopáticos constatados, mas são necessários estudos mais detalhados, com o isolamento dos aleloquímicos. No presente estudo, os efeitos alelopáticos foram observados tanto na germinação quanto no crescimento inicial da plântula de alface, sendo o efeito mais drástico sobre o crescimento inicial do que sobre a germinação.

\section{CONCLUSÃO}

Os extratos de folhas e de vagens de $\boldsymbol{C}$. ferrea, obtidos a quente $\left(100^{\circ} \mathrm{C}\right)$ reduzem a porcentagem de germinação de $\boldsymbol{L}$. sativa. Os extratos de folhas, cascas e vagens maduras de $\boldsymbol{C}$. ferrea apresentam atividade alelopática sobre o desenvolvimento de plântulas de alface, com o aparecimento de plântulas anormais e redução do comprimento da parte aérea e da raiz.

\section{AGRADECIMENTOS}

Ao Conselho Nacional de Desenvolvimento Científico e Tecnológico (CNPq), pela concessão de bolsa de produtividade a segunda autora.

\section{REFERÊNCIAS}

BORELLA et al. Efeito alelopático de extratos aquosos de Persea americana Mill. sobre Lactuca sativa L. Revista Brasileira de Biociências, Porto Alegre, v.7, n.3, p.260265, 2009. Disponível em: http://www6.ufrgs.br/seerbio/ojs/ index.php/rbb/article/view/1236/871. Acesso em: 15 nov. 2011.

BRASIL, Ministério da Agricultura e Reforma Agrária. Regras para análise de sementes. Brasília: SNAD/CLAV, 2009. 395p.

CARMO, M.S.F. et al. Alelopatia de extratos aquosos de canelasassafrás (Ocotea odorífera (Vell.) Rohwer). Acta Botânica Brasilica, Feira de Santana, v.21, n.3, p. 697-705, 2007. Disponível em: <http://www.scielo.br/pdf/abb/v21n3/a16v21n3.pdf>. Acesso em: 17 nov 2011. doi:10.1590/S0102-33062007000300016.

CENTENARO, C. et al. Contribuição ao estudo alelopático de Erythrina velutina Willd:, Fabaceae. Revista Brasileira de Farmacognosia, Curitiba, v.19, n.1b, p.304-308, 2009. Disponível em: <http://www.scielo.br/pdf/rbfar/v19n1b/ a21v191b.pdf>. Acesso em: 10 out. 2011. doi:10.1590/S0102695X2009000200021.

COELHO, M.F.B. et al. Atividade alelopática de extrato de sementes de juazeiro. Horticultura Brasileira, Vitória da Conquista, v.29, n.1, p.108-111, 2011. Disponível em: <http:/ /www.abhorticultura.com.br/Revista/Revista_29_1/ CC2043.pdf>. Acesso em: 28 ago. 2011. doi:10.1590/S010205362011000100018 .

DELACHIAVE, M.E.A. et al. Efeitos alelopáticos de gramaseda (Cynodon dactylon) na germinação de sementes de pepino, milho, feijão e tomate. Revista Brasileira de Sementes, Londrina, v.21, n.2, p.194-197, 1999. Disponível em: <http:/ /www.abrates.org.br/revista/artigos/1999/v21n1/artigo29.pdf >. Acesso em: 28 ago. 2011.

FERREIRA, A.G.; AQÜILA, M.E.A. Alelopatia: uma área emergente da ecofisiologia. Revista Brasileira de Fisiologia Vegetal, Campinas, v.12, n.esp., p.175-204, 2000. Disponível em: <http://www.uv.mx/personal/tcarmona/files/2010/08/Gui-yAlvez-1999.pdf>. Acesso em: 18 ago. 2011.

FERREIRA, D.F. SISVAR: um programa para análises e ensino de estatística. Revista Científica Symposium, Lavras, v.6, n.2, p.36-41, 2008. Disponível em: <http://www.fadminas.org.br/ symposium/12_edicoes/artigo_5.pdf>. Acesso em: 18 set. 2011.

FRASSON, A.P.Z. et al. Caracterização físico-química e biológica do caule de Caesalpinia ferrea Mart. Revista Brasileira de Farmacognosia, Curitiba, v.13, n.1, p.35-39, 
2003. Disponível em: <http://www.scielo.br/pdf/rbfar/v13n1/ a04v13n1.pdf $>$. Acesso em: 23 set. 2011. doi:10.1590/S0102$695 X 2003000100004$.

GATTI, A.B. et al. Atividade alelopática de extratos aquosos de Aristolochia esperanzae $O$. Kuntze na germinação e no crescimento de Lactuca sativa L. e Raphanus sativus L. Acta Botânica Brasílica, Feira de Santana, v.18, n.3, p.459-472, 2004. Disponível em: <http://www.scielo.br/pdf/abb/v18n3/ v18n3a06.pdf>. Acesso em: 12 set. 2011. doi: 10.1590/S010233062004000300006

GATTI, A.B. et al. Allelopathic effects of aqueous extracts of Artistolochia esperanzae O. Kuntze on development of Sesamum indicum L. seedlings. Acta Botânica Brasílica, Feira de Santana, v.24, n.2, p.454-461. 2010. Disponível em: $<$ http://www.scielo.br/pdf/abb/v24n2/a16v24n2.pdf $>$. Acesso em: 27 out. 2011. doi: 10.1590/S0102-33062010000200016.

GIOTTO A.C. et al. Efeito alelopático de Eugenia dysenterica Mart. ex DC. Berg. (Myrtaceae) na germinação e no crescimento de Lactuca sativa L. (Asteraceae). Revista Brasileira de Biociências, Porto Alegre, v.5, n.2, p.600-602, 2007. Disponível em: <http://www6.ufrgs.br/seerbio/ojs/index.php/rbb/ article/view/526/449>. Acesso em: 12 dez. 2011.

LABOURIAU, L.F.G.; AGUDO, M. On the physiology of seed germination in Salvia hispanica L.I. Temperatura effects. Anais da Acadêmia Brasileira de Ciências, Rio de Janeiro, v.59, p.37-56, 1987.

LORENZI, H.; MATOS, F.J.A. Plantas medicinais do Brasil: nativas e exóticas. 2.ed. Nova Odessa, SP: Instituto Plantarum, 2008. 544p.

MAGUIRE, J.D. Speed of germination-aid in selection evaluation for seedling emergence and vigor. Crop Science, Madison, v.2, p.176-177, 1962.

MARASCHIN-SILVA, F.; AQÜILA, M.E.A. Contribuition to the study of native species allelopathic potential. Revista Árvore, Viçosa, v.30, p.547-555, 2006. Disponível em: <http:/ /www.scielo.br/pdf/rarv/v30n4/31675.pdf>. Acesso em: 27 nov. 2011. doi: 10.1590/S0100-67622006000400007.

MARASCHIN-SILVA, F.; AQÜILA, M.E.A. Potencial alelopático de Dodonaea viscosa (L.) Jacq. Iheringia, Rio de Janeiro, v.60, p.91-98, 2005. Disponível em: <http:// www.fzb.rs.gov.br/publicacoes/iheringia-botanica/Ih60p9198.pdf>. Acesso em: 20 dez. 2011.

MARCOS FILHO, J. Fisiologia de sementes de plantas cultivadas. Piracicaba: FEALQ, 2005. 495p.

OLIVEIRA, A.K. et al. Alelopatia em extratos de frutos de juazeiro (Ziziphus joazeiro Mart. - Rhamnaceae). Acta Botânica Brasílica, Feira de Santana, v.23, n.4, p.1186-1189, 2009. Disponível em: <http://acta.botanica.org.br/index.php/ acta/article/viewFile/1219/255>. Acesso em: 28 out. 2011. doi: 10.1590/S0102-33062009000400029.

PERIOTTO, F. et al. Efeito alelopático de Andira humilis Mart. ex Benth na germinação e no crescimento de Lactuca sativa L. e Raphanus sativus L. Acta Botânica Brasílica, Feira de Santana, v.18, p.425-430. 2004. Disponível em: <http:/ /www.scielo.br/pdf/abb/v18n3/v18n3a03.pdf>. Acesso em: 23 out. 2011. doi: 10.1590/S0102-33062004000300003.

RÊGO JÚNIOR, N.O. et al. Compostos bioativos e atividade antioxidante de extratos brutos de espécies vegetais da caatinga. Brazilian Journal of Food Technology, Campinas, v.14, n.1, p.50-57, 2011. Disponível em: <http://www.ital.sp.gov.br/ bj/artigos/html/busca/PDF/v14n1444a.pdf>. Acesso em: 21 nov. 2011. doi: 10.4260/BJFT2011140100007.

RICE, E.L. Allelopathy. 2.ed. New York: Academic, 1984. 422p.

SANTOS, A.M.; DANTAS, I.C. Possíveis efeitos tóxicos das plantas que constituem a bebida "pau-do-índio". Revista de Biologia e Farmácia, João Pessoa, v.2, n.2, p.63-81, 2008. Disponível em: <http://eduep.uepb.edu.br/biofar/n2v2/07possiveis_efeitos.pdf $>$. Acesso em: 29 out. 2011.

SILVA, W.A. et al. Efeito alelopático de extrato aquoso de Amburana cearensis A. Smith na germinação e crescimento de sementes de sorgo (Sorghum bicolor L.). Agropecuária Científica no Semi-árido, Campina Grande, v.2, n.1, p.4854, 2006. Disponível em: <http://150.165.111.246/ojs-patos/ index.php/ACSA/article/view/22/pdf $>$. Acesso em: 25 nov. 2011.

SILVEIRA, P.F. et al. Potencial alelopático do extrato aquoso de cascas de jurema preta no desenvolvimento inicial de alface. Revista Caatinga, Mossoró, v.25, n.1, p.20-27, 2012. Disponível em: <http://periodicos.ufersa.edu.br/revistas/ index.php/sistema/article/view/2027>. Acesso em: 25 out. 2011.

SOUZA FILHO, A.P.S. et al. Atividade alelopática de extratos brutos de três espécies de Copaifera (LeguminosaeCaesalpinioideae). Planta Daninha, Viçosa, v.28, n.4, p.743751, 2010. Disponível em: <http://www.scielo.br/pdf/pd/v28n4/ v28n4a06.pdf $>$. Acesso em: 25 ago. 2011. doi: 10.1590/ S0100-83582010000400006

SOUZA, F. et al. Allelopathic potential of bark and leaves of Esenbeckia leiocarpa Engl. (Rutaceae). Acta Botânica Brasílica, Feira de Santana, v.24, n.1, p.169-174, 2010. Disponível em: <http://www.scielo.br/pdf/abb/v24n1/16.pdf>. Acesso em: 21 dez 2011. doi: 10.1590/S010233062010000100016 .

TAIZ, L.; ZEIGER, E. Fisiologia vegetal. 4.ed. Porto Alegre: Artmed, 2006. 722p.

TRUGILLO et al. Determinação do teor de taninos na casca de Eucalyptus spp. Cerne, Lavras, v.9, n.2. p.246-254, 2003. Disponível em: <http://www.dcf.ufla.br/cerne/administracao/ publicacoes/m199v9n2o11.pdf>. Acesso em: 28 set.2011.

WANDSCHEER, A.C.D.; PASTORINI, L.H. Interferência alelopática de Raphanus raphanistrum L. sobre a germinação de Lactuca sativa L. e Solanum licopersycon L. Ciência Rural, Santa Maria, v.38, p.949-953, 2008. Disponível em: $<$ http://www.scielo.br/pdf/cr/v38n4/a07v38n4.pdf >. Acesso em: 21 ago. 2011. doi: 10.1590/S0103-84782008000400007. 